ON THE RECORD

c(Wouldn't it be fascinating to take a Fourier transform of those waves?')

The words with which science blogger Sean Carroll, of Cosmic Variance, captured the heart of Jennifer Ouellette, who blogs at Cocktail Party Physics, while watching a Pacific sunset. They are to marry next year.

\section{(CThis is a guy who takes a neuropeptide and a prairie vole and spins from them science fiction.”}

Journalist Amanda Schaffer is outraged that Eric Keroack has been chosen to head the US federal familyplanning programmes. Keroack says that research in voles has led him to believe that promiscuity makes people less able to bond with their children.

\section{ccFor the time-being our immediate solution is to send them to the taxidermists.)}

Muhedin Abdulaziz, of Addis Ababa's zoo, on the problem of having more Abyssinian lion cubs than the zoo can handle.

\section{SCORECARD}

\section{Amateur fusion}

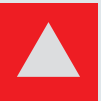

Schoolboy Thiago

Olson of Oakland

Township, Michigan,

has reportedly become the 18 th amateur scientist to achieve a low level of nuclear fusion using a home-made set-up.

\section{NUMBER CRUNCH}

US\$20 million is the ticket price for a trip to the International Space Station on a Russian spacecraft.

2,080 is the number of years a Russian cosmonaut would have to bank his or her entire $\$ 810$-a-month salary to save that much money.

O is the number of cosmonauts recruited from Russia's top universities through outreach programmes this year.

Sources: Slate, Detroit Free Press, The Times.

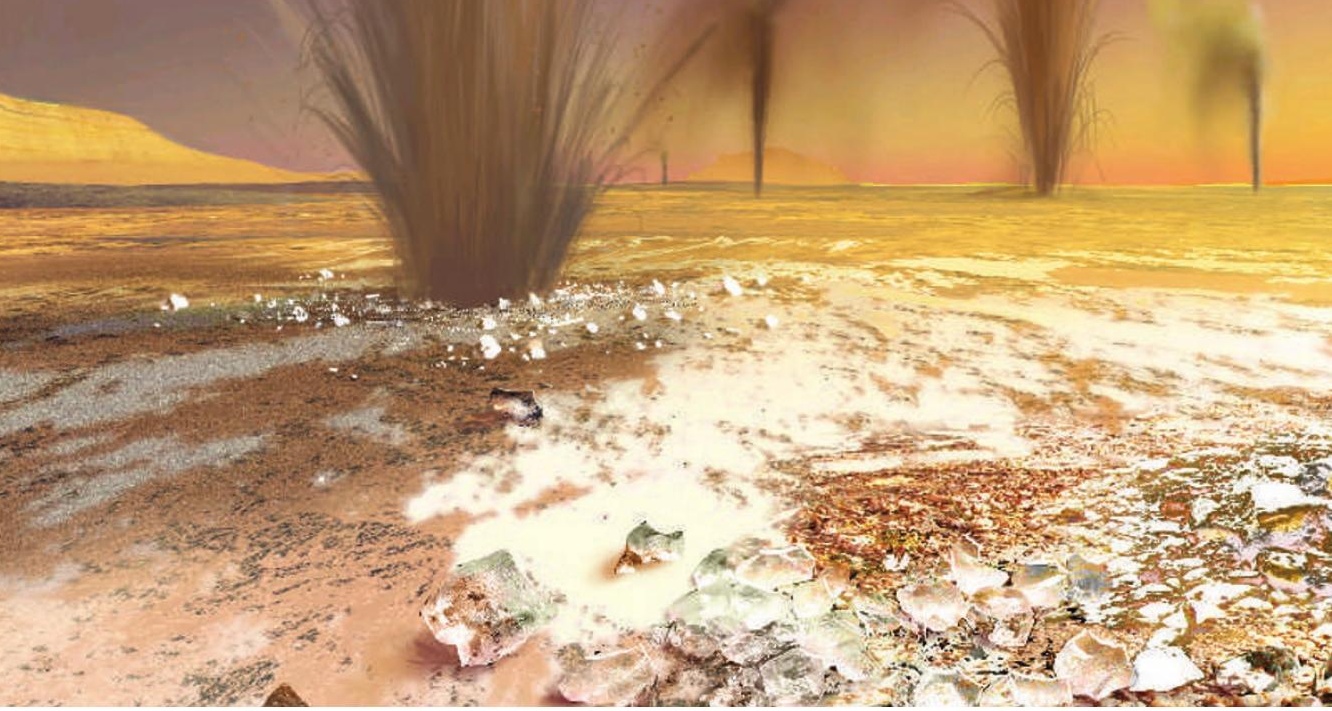

Spouting forth: artist's impression of dusty gas jets found by Mars Global Surveyor at Mars's south pole.

\title{
A space dilemma: extend missions or start afresh?
}

Scientists said a sad goodbye last week to the orbiting spacecraft Mars Global Surveyor, which had gone missing two weeks earlier.

The mission has been portrayed as heroically long-lived, surpassing all expectations and being extended four times until scientists finally lost contact with it just before the tenth anniversary of its launch. It's a familiar story for NASA missions - the Mars rovers Spirit and Opportunity have both lasted ten times longer than their 90-day intended lifetimes and continue to roam the planet, and the agency is spending billions of dollars on a shuttle mission to keep the Hubble Space Telescope running against all the odds.

But however attached we might get to old missions, does it really make financial sense to run them until they break, get lost or fall into a hole too big to get out of?

Extending missions is a trade-off between wringing as much science as possible out of a craft and redirecting resources into new missions. And at NASA, keeping missions going is seen as well worth the money. An extended mission typically costs a few million dollars a year to run, whereas a new launch can cost hundreds of millions or more. Critics might argue that the most important results from the Mars rovers, such as clinching the case that liquid water once existed on the planet, came from the early part of the mission. But Bruce Banerdt, rover project scientist at the Jet Propulsion Laboratory in Pasadena, California, claims that every time the rovers move a few hundred metres, it's like landing a new lander: "It's scientifically cost-effective."

James Green, director of NASA's planetaryscience division, acknowledges that with an extended mission you are restricted to the science the craft was designed for, rather than choosing what needs to done. But Green insists that, because they are so much cheaper than a 


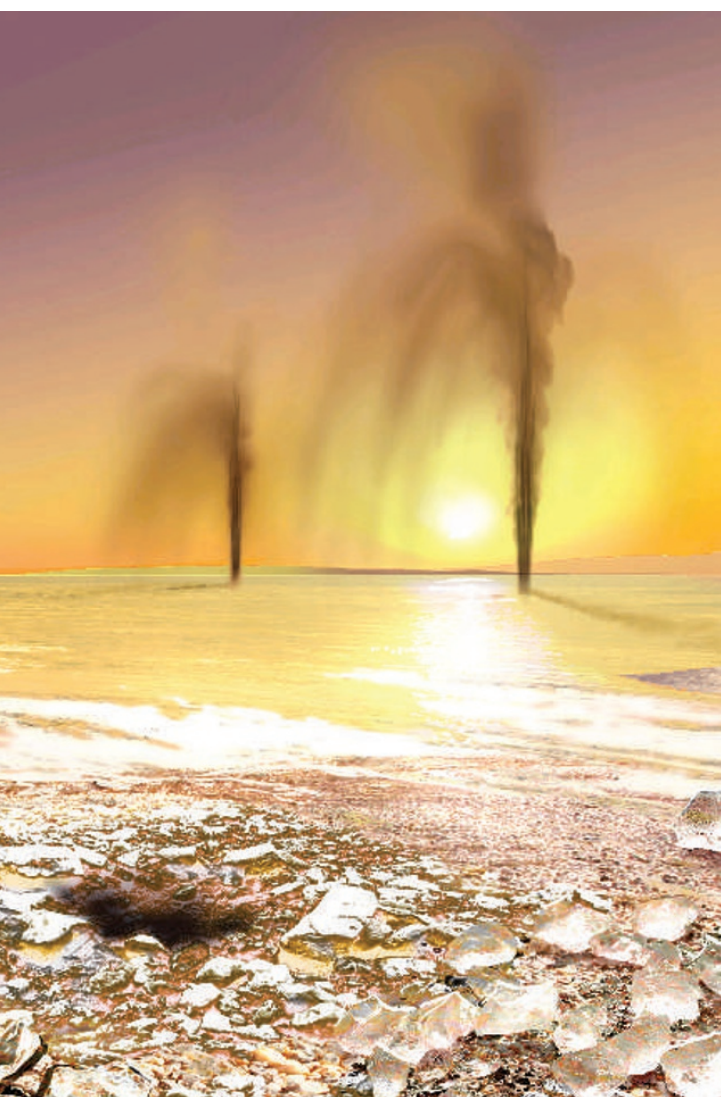

new mission, extended missions are worth the effort. NASA's mission scientists bid for extensions once the primary science objectives have been fulfilled, and missions are judged on their scientific impact to date: "science per dollar", he says.

Possible extensions are not mentioned in the initial mission planning stages, so designing missions to last longer than planned is an easy way for mission scientists to buy into future budgets. There's also the public-relations value - in terms of public image, it is better to say a mission will last for five years and then extend its life, than to say it will last for ten years and lose it after nine. The latter scenario would be seen as a failure, says Lori Garver, a former NASA associate administrator. She sees no problem with deliberately underestimating the life of a spacecraft. By the time a mission is ready to be extended, the big pots of money have already been spent on it, she says.

Attitudes at the European Space Agency (ESA), which has a smaller budget and flies fewer missions (17 spacecraft are currently operational), are slightly different. Letting missions run until they fail, with no predefined notion of how long that might take, is not necessarily a sustainable strategy, says Giovanni

\section{SPACE-AGE RELAY}

NASA lost contact with Mars Global Surveyor on 2 November. Despite bombarding the craft with more than 800 command files, the last scientists heard was a possible faint signal on 5 November.

Mars Global Surveyor made the first reliable topographic map of the whole planet, and revealed swathes of the surface in great detail. It also allowed the first analysis of Mars's ancient magnetic fields. But perhaps its most dramatic discovery was of fresh gullies in the walls of some craters and on other slopes that seemed to have been formed by fluid flow.

More recently, the craft was helping Mars Reconnaissance Orbiter, which arrived in March, to scout out a landing spot for the next generation of Mars probes: Phoenix, due to arrive in 2008, and Mars Science Lab, which will touch down in 2010.

Mars Reconnaissance Orbiter's mission is scheduled to run until 2010, but is expected to last far longer. The planet is currently circled by two other craft, NASA's Mars Odyssey and the European Space Agency's Mars Express. The overlap between Mars Global Surveyor and these missions marks the first time that one craft orbiting a planet (other than Earth) has passed the baton to another.

Bignami, chairman of ESA's space-science advisory commission. "By continuing to extend missions you eat into resources that could be used to do something new," he explains.

Up to $10 \%$ of ESA's budget is spent on keeping old missions alive, and Bignami says that no missions have been ended while they were still operational. But the agency expects that with several new craft due to launch in the next few years - including BepiColombo bound for Mercury, and Gaia, which will create a three-dimensional map of our Galaxy - it will become more difficult to keep old missions running.

ESA approves missions for two years at a time, and some are definitely worth extending, says Bignami; for example, the XMM-Newton X-ray satellite, which is looking at black holes and exploding stars. He reckons that other missions might be easier to finish, such as Venus Express - there's a limit to how much useful data can be gathered by continuing to orbit Venus with the same instruments.

Although many are sad to see Mars Global Surveyor go, Bignami also anticipates some happy faces at NASA, as an old mission is finally abandoned and new ones can begin.

Katharine Sanderson

See Editorial, page 520. 